\title{
Reduction in induction motor heating fed by a new PWM technique: results obtained in laboratory experiments.
}

\author{
M. J. Meco-Gutiérrez ${ }^{(1)}$, A. Ruiz Gonzalez ${ }^{(1)}$, F. Vargas-Merino ${ }^{(1)}$, J.R. Heredia-Larrubia ${ }^{(2)}$ \\ E.T.S. Ingenieros Industriales. (1) Electric Engineering Department \\ (2) Electronic Technology Department \\ Universidad de Málaga \\ Plaza de El Ejido s/n \\ 29013 Malaga. Spain pacuma@gmail.com
}

\begin{abstract}
This paper presents the laboratory results on heat produced in an induction motor stator when this is fed by a controlled inverter using a new PWM technique designed by the authors, compared to the heat produced in the same motor fed by more traditional PWM techniques.
\end{abstract}

\section{Key words}

Harmonics,PWM,signal quality, HIPWM, AC motors

\section{Introduction}

At present, inverters are commonly used to control the speed of induction motors.

Inverters are in charge of regulating the three-phase voltage fed to induction motors both in terms of amplitude and frequency, following a specific control strategy in each case.

The output voltage can be controlled in different ways. The most common method consists of controlling the pulse width applied to the electronic switches, whether these are thyristors, MOSFETs, IGBTs, etc.

In any event, the wave frequency spectrum obtained at the output contains many harmonics. These harmonics increase losses [1]-[3] and cause heat problems in the machine [4], resulting in wear of the insulation covering the conductors and reducing the system's performance. Another adverse effect is that magnetic fields are produced in the yoke, some of which rotate in the same direction as and others in the opposite direction to the main field, causing par fluctuations, vibration and noise [5].

Therefore, these harmonics should be reduced. The first option to achieve this is the use of filters, thus reducing or eliminating the most significant harmonics. However, there are also other possibilities, such as more or less sophisticated techniques to control the inverter switch trigger, which aim to generate signals containing few harmonics [6]. The most common technique is pulse width modulation (PWM).

The most classic generated pulse width modulation technique involves a high frequency triangular signal as a carrier, and a sinusoidal modulator with fundamental frequency $\omega_{\mathrm{m}}$ [7]-[8]. Comparing the two gives the sinusoidal pulse width

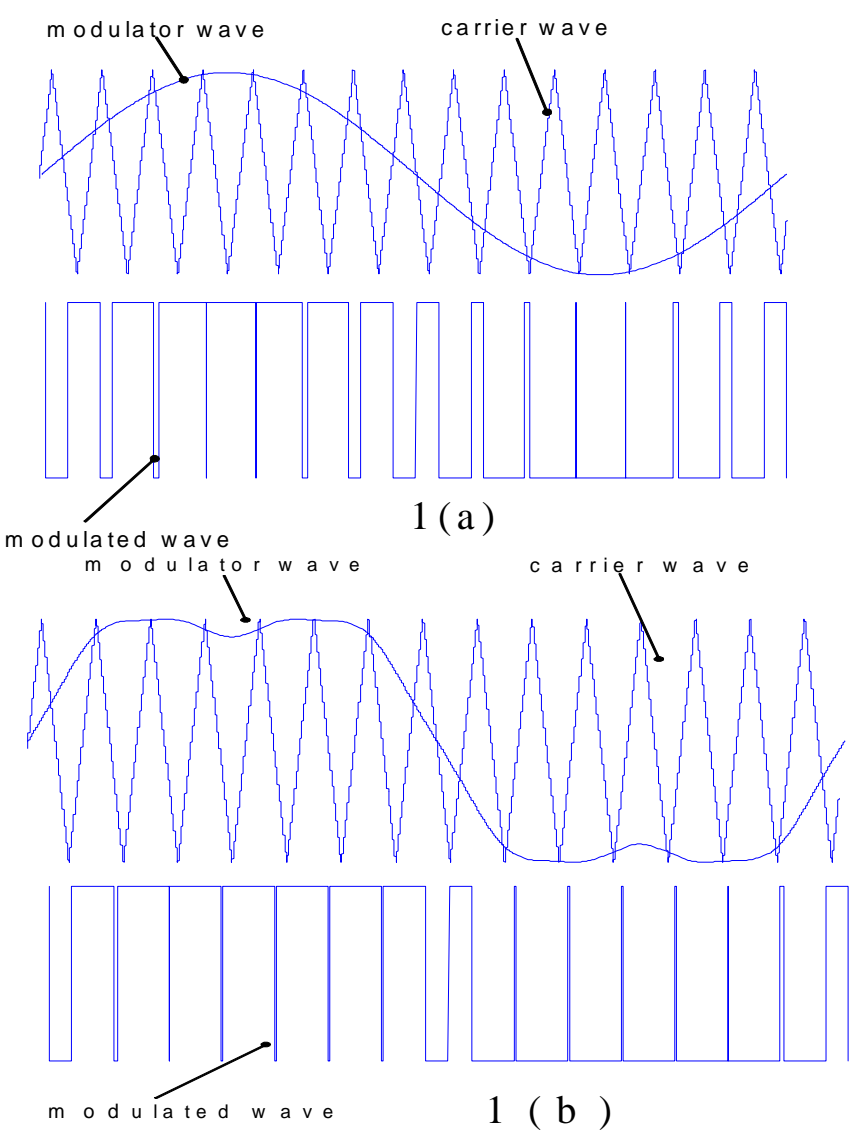

Fig. 1(a). Senoidal pulse width modulation (SPWM); modulating wave,

Fig. 1(b). Harmonic injection pulse width modulation (HIPWM); modulating wave, carrier wave and resulting modulated wave. 


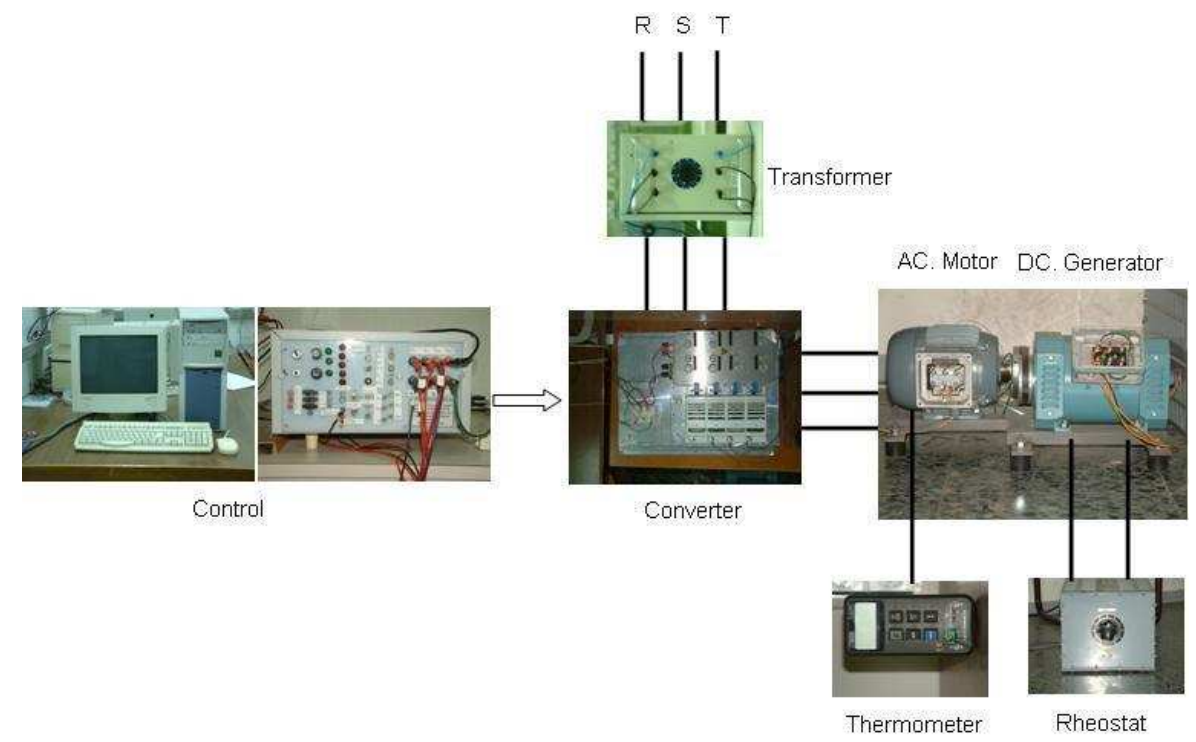

Fig. 2 Laboratory experimental setup

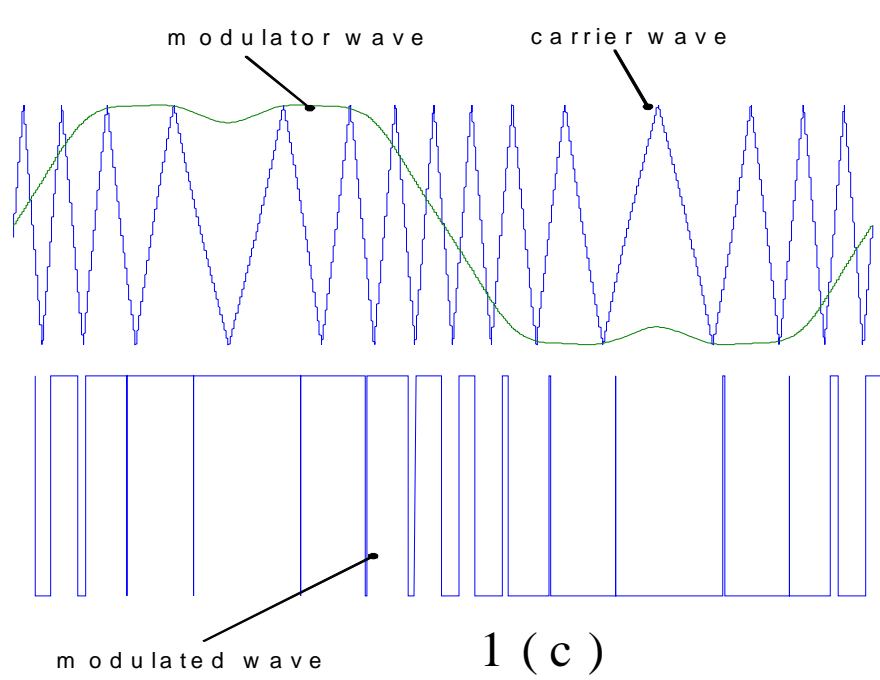

Fig. 1(c). Harmonic Injection Pulse Width Modulation and Frequency Modulated Triangular Carrier" (HIPWM-FMTC); modulating wave, carrier wave and resulting modulated wave.

modulated signal (SPWM). The main disadvantage of this technique is that it generates a fundamental term with small amplitude and a significant amount of undesired harmonics.

There exists a series of more advanced techniques which increase the value of the fundamental term and decrease harmonics of the resulting modulated signal in comparison to the SPWM. One of these techniques is born out of the SPWM, and it consists of overmodulating the sinusoidal modulator whose frequency is $\omega_{\mathrm{m}}$, as well as to the third and ninth harmonic with specific amplitudes [9]; resulting in Harmonic Injection Pulse Width Modulation (HIPWM).
An important parameter in the PWM is the so-called modulation order $(\mathrm{M})$, which is the ratio between the carrier frequency and the modulator frequency. This parameter also represents the number of pulses per period of the modulated wave applied to the inverter's electronic switches.

\section{Brief description}

In this article we propose the results obtained on the heating of a motor using an alternative technique which involves the same number of commutations per unit of time, while generating an output signal with a significant reduction in harmonics compared to the PWM techniques described above.

This new technique uses an identical modulator to the one used with the HIPWM technique, and an instantaneous frequency triangular signal, $\omega_{i}$, as the carrier [10]:

$$
\omega_{i}=\omega_{c}-k_{f} \cdot\left(\sin \left(\omega_{m} t\right)\right)^{2}
$$

Where $\omega_{\mathrm{c}}$ is a given central frequency around which $\omega_{\mathrm{i}}$ varies, and $\mathrm{k}_{\mathrm{f}}$ a modulation constant.

This technique is called "Harmonic Injection Pulse Width Modulation and Frequency Modulated Triangular Carrier" (HIPWM-FMTC)".

Fig. 1(a),1(b) and 1(c) shows the waveforms of the modulator, carrier and modulated signal for $\mathrm{M}=15$, obtained using the three aforementioned techniques under comparison. 


\begin{tabular}{|c|c|c|c|}
\hline $\begin{array}{c}\text { Time } \\
(\mathrm{min})\end{array}$ & SPWM & HIPWM & $\begin{array}{c}\text { HIPWM } \\
\text {-FMTC }\end{array}$ \\
\hline 0 & 22.0 & 22.0 & 22.0 \\
\hline 10 & 25.3 & 25.3 & 25.2 \\
\hline 20 & 28.2 & 28.1 & 28.1 \\
\hline 30 & 30.2 & 30.0 & 29.5 \\
\hline 40 & 31.2 & 31.0 & 30.4 \\
\hline 50 & 31.9 & 31.7 & 31.1 \\
\hline 60 & 32.3 & 32.0 & 31.4 \\
\hline 70 & 32.4 & 32.1 & 31.5 \\
\hline 80 & 32.4 & 32.1 & 31.5 \\
\hline 90 & 32.5 & 32.2 & 31.6 \\
\hline
\end{tabular}

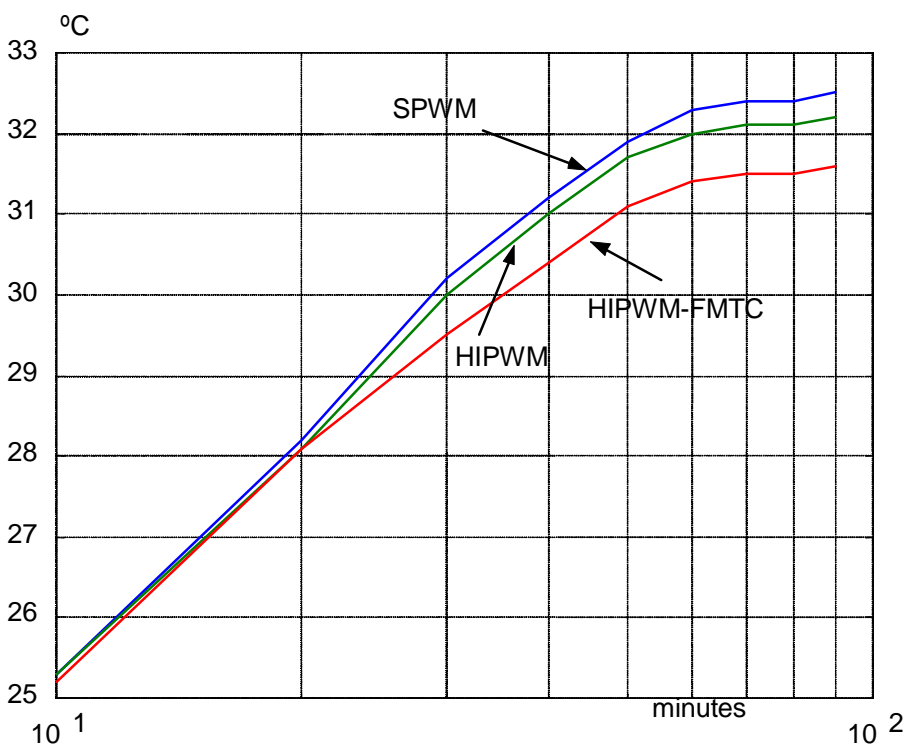

Fig. 3(a) Table and graph of temperatures measured in the AC-motor stator in the test performed With $50 \%$ charge.

\section{Description of scheme}

The block diagram of the experimental setup at the Universidad de Málaga laboratory is shown in fig. 2; including the following components: The control block, which is in charge of generating the trigger pulses for the inverter's electronic switches, in accordance with the three techniques that are going to be compared: SPWM, HIPWM and HIPWMFMTC. Modulation order $\mathrm{M}=27$ is used in each case.

Skiip 342GDL120-411CTV Semikron inverter, with IGBT switches and antiparallel diodes. This feeds an eAM 90SY rEx three-phase induction model; $1 \mathrm{~kW}, 380 / 220 \mathrm{~V} ; 50 \mathrm{~Hz}$, supplied

\begin{tabular}{|c|c|c|c|}
\hline $\begin{array}{c}\text { Time } \\
(\mathrm{min})\end{array}$ & SPWM & HIPWM & $\begin{array}{c}\text { HIPWM- } \\
\text { FMTC }\end{array}$ \\
\hline 0 & 22.0 & 22.0 & 22.0 \\
\hline 10 & 23.9 & 23.9 & 23.9 \\
\hline 20 & 26.8 & 26.6 & 26.2 \\
\hline 30 & 27.3 & 27.2 & 26.8 \\
\hline 40 & 27.7 & 27.6 & 27.2 \\
\hline 50 & 28.0 & 27.8 & 27.3 \\
\hline 60 & 28.1 & 27.9 & 27.4 \\
\hline 70 & 28.1 & 27.9 & 27.4 \\
\hline 80 & 28.1 & 27.9 & 27.4 \\
\hline 90 & 28.1 & 27.9 & 27.5 \\
\hline
\end{tabular}

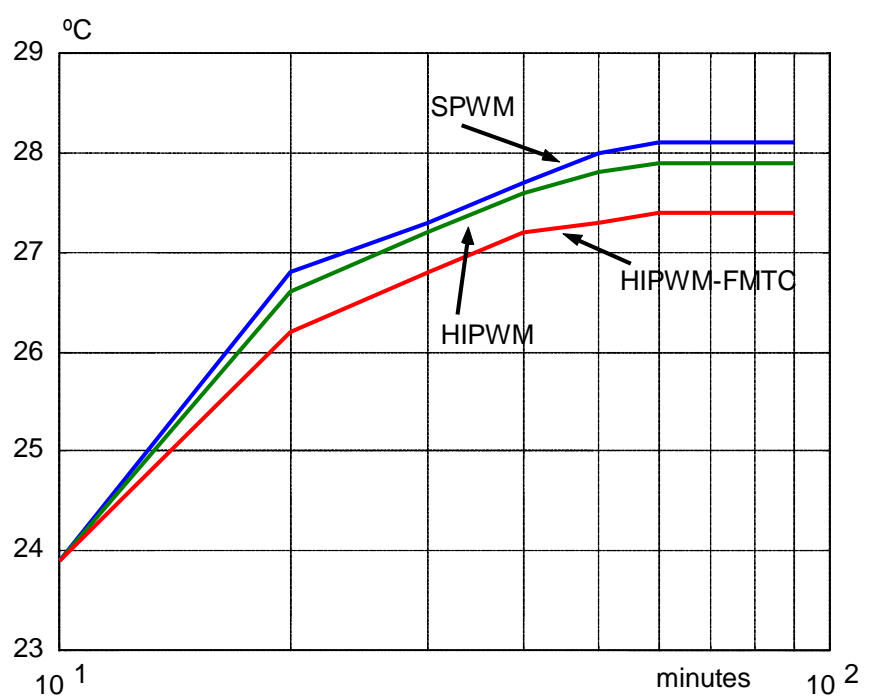

Fig . 3(b) Table and graph of temperatures measured in the AC-motor stator in the test performed With $25 \%$ charge.

by the AEG factory in Martorell (Barcelona, Spain). This motor has an 8-mm diameter hole in the centre of the casing, which travels inwards in a radial direction in the stator's magnetic shield to a depth of $1 \mathrm{~mm}$ from the start of the slot. An SK6 thermocouple probe is inserted in the hole. This probe as a practically constant coefficient of $40 \mu \mathrm{V} /{ }^{\circ} \mathrm{C}$ and is specially designed to reach awkward areas. The temperature is taken using a C.A864 digital probe manufactured by Chauvin Arnoux. Both the thermocouple and the thermometer meet IEC 584, NFC 42-321 and 322 standards. To charge the induction motor, a VDA $90 \mathrm{M}$ self-exciting dynamo manufactured by Vascat S.A. is used, which feeds an Alecop variable rheostat.

By adjusting the variable rheostat, two tests are run: one at $50 \%$ of the AC-motor nominal power and another at $25 \%$ of the nominal power. The digital thermometer records the temperature taken by the probe inserted in the casing hole 
every ten minutes. This is repeated until few changes are noticed.

Figure $3 \mathrm{a}$ and $3 \mathrm{~b}$ shows the results obtained from the temperature measurements using the three techniques for the charges considered.

It is clear from the tables and the graphs that the temperature reached inside the stator when both charges are applied is lower with the proposed technique.

\section{Conclusion}

The technique designed by the authors has a clear advantage over the other traditional PWM techniques in terms of heating the motor. This is due to the lower content of harmonics.

\section{References}

[1] Sagarduy J., Moses A. J. and Anayi F. J. "Eddy Current Losses in Electrical Steels Subjected to Matrix and Classical PWM Excitation Waveforms". Magnetics, IEEE Transactions on Volume 42, Issue 10, Oct. 2006 Page(s):2818 - 2820 .

[2] Jae-Woo Kim; Byung-Taek Kim; Byung Il Kwon. "Optimal stator slot design of inverter-fed induction motor in consideration of harmonic losses". Magnetics, IEEE Transactions on. Volume 41, Issue 5, May 2005 Page(s):2012 - 2015.

[3] Marcic, T.; Sumberger, G.; Hadziselimovic, M.; Zagradisnik, I. "Analysis of Induction Motor Drive Losses in the Field-Weakening Region". 12th
International Power Electronics and Motion Control Conference. Aug. 2006 Page(s): 1173 - 1178.

[4] Fouladgar, J.; Chauveau, E. "The influence of the harmonics on the temperature of electrical Machines". Magnetics, IEEE Transactions on.Volume 41, Issue 5, May 2005 Page(s):1644 - 1647.

[5] Plotkin, Y.; Stiebler, M.; Hofmeyer, D "Sixth torque harmonic in PWM inverter-fed induction drives and its compensation" Industry Applications, IEEE Transactions on Volume 41, Issue 4, July-Aug. 2005 Page(s):1067 1074.

[6] Bowes, S, R. and Grewal , S. "Modulation Strategy for Single Phase PWM Inverters". Electronics Letters. Vol 3 $\mathrm{n}^{\circ}$ 5, March 1998.

[7] Holtz, J. "Pulsewidth Modulation-a Survey". IEEE Transactions on Industrial Electronics. Vol. 39, December 1992.

[8] Holtz, J. "Pulsewidth Modulation for Electronic Power Conversion". Proceedings of the IEEE. Vol. 82, August 1994.

[9] Boost, M. A.; Ziogas, P. D. "State-of-the-Art Carrier PWM Techniques: A Critical Evaluation". IEEE Transactions on Industry Applications. Vol. 24, $\mathrm{n}^{\circ} 2$ March/April 1988.

[10] Meco Gutierrez, M.J. "Técnica de modulación de ancho de pulso con inyección de armonicos y portadora triangular modulada en frecuencia" $\mathrm{Ph}$. D. University of Malaga (Spain) october 2003. 